\title{
Generalized kinetic equation with spatio-temporal nonlocality
}

\author{
Kostrobij P. P. ${ }^{1}$, Markovych B. M. ${ }^{1}$, Ryzha I. A. ${ }^{1}$, Tokarchuk M. V. ${ }^{1,2}$ \\ ${ }^{1}$ Lviv Polytechnic National University, \\ 12 S. Bandera Str., 79013, Lviv, Ukraine \\ ${ }^{2}$ Institute for Condensed Matter Physics \\ of the National Academy of Sciences of Ukraine, \\ 1 Svientsitskii Str., 79011, Lviv, Ukraine
}

(Received 5 September 2019; Revised 12 October 2019; Accepted 16 October 2019)

\begin{abstract}
A non-Markov kinetic equation with fractional derivatives for a nonequilibrium oneparticle distribution function is obtained. The resulting equation contains the generalized diffusion and friction coefficients in the space of coordinates and momentums of particles. This equation can be used, in particular, for mathematical modeling of kinetic processes of particle transport in porous media with fractal structure.
\end{abstract}

Keywords: kinetic equation, spatio-temporal nonlocality, nonequilibrium distribution function, Renyi statistics.

2000 MSC: $82 \mathrm{C} 05,82 \mathrm{C} 70$

UDC: 538.93

DOI: $10.23939 / \mathrm{mmc} 2019.02 .289$

\section{Introduction}

Studies of nonequilibrium processes with spatio-temporal nonlocality are relevant in the statistical physics of soft matter. Mathematical modeling of diffusion (sub-, super-diffusion) electrodiffusion transfer processes in porous and complex nano-structured (with characteristic fractality) systems requires the use of transfer equations with significant spatial inhomogeneity and temporal memory. In our works [1-9] a statistical approach to obtain generalized spatio-temporal nonlocal transfer equations was developed by using the Zubarev nonequilibrium statistical operator method [10-13] and the Liouville equation with fractional derivatives $[14,15]$. In particular, the generalized diffusion equations of Cattaneo [2,4], Cattaneo-Maxwell [5] and electrodiffusion [6-9] with spatio-temporal fractional derivatives were obtained.

In this paper a generalized kinetic equation with spatio-temporal fractional derivatives for a nonequilibrium one-particle distribution function of a classical system is obtained on the basis of [4]. It is important to note that the chain of BBGKY kinetic equations with fractional derivatives was obtained in works $[14,16,17]$ and the kinetic equations in the Klimontovich's approach for systems with fractal structure, in particular for describing the diffusion processes in the space of coordinates and momentums, were obtained in works $[18,19]$.

The second section presents a method for obtaining the generalized spatio-temporal nonlocal transport equations by using the Liouville equation with fractional derivatives and the Zubarev nonequilibrium statistical operator method in the Renyi statistics. On this basis, a new generalized kinetic equation with fractional derivatives for a nonequilibrium one-particle distribution function is obtained in the third section.

\section{Liouville equation with fractional derivatives for classical system of particles}

We use the Liouville equation with fractional derivatives obtained by Tarasov in Refs. $[14,15]$ for a nonequilibrium particle function $\rho\left(x^{N} ; t\right)$ of a classical system 


$$
\frac{\partial}{\partial t} \rho\left(x^{N} ; t\right)+\sum_{j=1}^{N} D_{\boldsymbol{r}_{j}}^{\alpha}\left(\rho\left(x^{N} ; t\right) \boldsymbol{v}_{j}\right)+\sum_{j=1}^{N} D_{\boldsymbol{p}_{j}}^{\alpha}\left(\rho\left(x^{N} ; t\right) \boldsymbol{F}_{j}\right)=0
$$

where $x^{N}=x_{1}, \ldots, x_{N}, x_{j}=\left\{\boldsymbol{r}_{j}, \boldsymbol{p}_{j}\right\}$ are dimensionless generalized coordinates, $\boldsymbol{r}_{j}=\left(r_{j 1}, \ldots, r_{j m}\right)$, and generalized momentum, $\boldsymbol{p}_{j}=\left(p_{j 1}, \ldots, p_{j m}\right)$, [20] of $j$ th particle in the phase space with a fractional differential volume element $[15,21] d^{\alpha} V=d^{\alpha} x_{1} \ldots d^{\alpha} x_{N}$. Here, $m=\frac{M r_{0}}{p_{0} t_{0}}, M$ is the mass of particle, $r_{0}$ is a characteristic scale in the configuration space, $p_{0}$ is a characteristic momentum, and $t_{0}$ is a characteristic time. $d^{\alpha}$ is a fractional differential [21] that is defined by

$$
d^{\alpha} f(x)=\sum_{j=1}^{2 N} D_{x_{j}}^{\alpha} f(x)\left(d x_{j}\right)^{\alpha}
$$

where

$$
D_{x}^{\alpha} f(x)=\frac{1}{\Gamma(n-\alpha)} \int_{0}^{x} \frac{f^{(n)}(z)}{(x-z)^{\alpha+1-n}} d z
$$

is the Caputo fractional derivative, [22-25] $n-1<\alpha<n, f^{(n)}(z)=\frac{d^{n}}{d z^{n}} f(z)$ with the properties $D_{x_{j}}^{\alpha} 1=0$ and $D_{x_{j}}^{\alpha} x_{l}=0,(j \neq l) . \quad \boldsymbol{v}_{j}$ are the fields of velocity, $\boldsymbol{F}_{j}$ is the force field acting on $j$ th particle. If $\boldsymbol{F}_{j}$ does not depend on $\boldsymbol{p}_{j}, \boldsymbol{v}_{j}$ does not depend on $\boldsymbol{r}_{j}$, and the Helmholtz conditions are satisfied,

$$
\frac{\partial v_{j}}{\partial p_{l}}-\frac{\partial v_{l}}{\partial p_{j}}=0, \quad \frac{\partial v_{j}}{\partial r_{l}}+\frac{\partial F_{l}}{\partial p_{j}}=0, \quad \frac{\partial F_{j}}{\partial r_{l}}-\frac{\partial F_{l}}{\partial r_{j}}=0
$$

we get

$$
\begin{gathered}
\frac{\partial}{\partial t} \rho\left(x^{N} ; t\right)+\sum_{j=1}^{N} \boldsymbol{v}_{j} D_{\boldsymbol{r}_{j}}^{\alpha} \rho\left(x^{N} ; t\right)+\sum_{j=1}^{N} \boldsymbol{F}_{j} D_{\boldsymbol{p}_{j}}^{\alpha} \rho\left(x^{N} ; t\right)=0, \\
\boldsymbol{v}_{j}=D_{\boldsymbol{p}_{j}}^{\alpha} H(\boldsymbol{r}, \boldsymbol{p}), \quad \boldsymbol{F}_{j}=-D_{\boldsymbol{r}_{j}}^{\alpha} H(\boldsymbol{r}, \boldsymbol{p}),
\end{gathered}
$$

where $H(\boldsymbol{r}, \boldsymbol{p})$ is a Hamiltonian of a system with fractional derivatives [20]. We get the Liouville equation in the form

$$
\frac{\partial}{\partial t} \rho\left(x^{N} ; t\right)+i L_{\alpha} \rho\left(x^{N} ; t\right)=0,
$$

where $i L_{\alpha}$ is the Liouville operator with the fractional derivatives,

$$
i L_{\alpha} \rho\left(x^{N} ; t\right)=\sum_{j=1}^{N}\left[D_{\boldsymbol{p}_{j}}^{\alpha} H(\boldsymbol{r}, \boldsymbol{p}) D_{\boldsymbol{r}_{j}}^{\alpha}-D_{\boldsymbol{r}_{j}}^{\alpha} H(\boldsymbol{r}, \boldsymbol{p}) D_{\boldsymbol{p}_{j}}^{\alpha}\right] \rho\left(x^{N} ; t\right) .
$$

A solution of the Liouville equation (4) will be found with the Zubarev nonequilibrium statistical operator method $[10,11]$. After choosing parameters of the reduced description, taking into account projections we present the nonequilibrium particle function $\rho\left(x^{N} ; t\right)$ (as a solution of the Liouville equation) in the general form

$$
\rho\left(x^{N} ; t\right)=\rho_{\text {rel }}\left(x^{N} ; t\right)-\int_{-\infty}^{t} e^{\varepsilon\left(t^{\prime}-t\right)} T\left(t, t^{\prime}\right)\left(1-P_{r e l}\left(t^{\prime}\right)\right) i L_{\alpha} \rho_{r e l}\left(x^{N} ; t^{\prime}\right) d t^{\prime},
$$

where $T\left(t, t^{\prime}\right)=\exp _{+}\left[-\int_{t^{\prime}}^{t}\left(1-P_{r e l}\left(t^{\prime}\right)\right) i L_{\alpha} d t^{\prime}\right]$ is the evolution operator in time containing the projection, $\exp _{+}$is ordered exponential, $\varepsilon \rightarrow+0$ after taking the thermodynamic limit, $P_{\text {rel }}\left(t^{\prime}\right)$ is the generalized Kawasaki-Gunton projection operator depended on a structure of the relevant statistical operator (distribution function), $\rho_{\text {rel }}\left(x^{N} ; t^{\prime}\right)$. By using the Zubarev nonequilibrium statistical operator method [10-12] and approach, [13] $\rho_{\text {rel }}\left(x^{N} ; t^{\prime}\right)$ will be found from the extremum of the Renyi 
entropy at fixed values of observed values $\left\langle\hat{P}_{n}(x)\right\rangle_{\alpha}^{t}$, taking into account the normalization condition $\langle 1\rangle_{\alpha, \text { rel }}^{t}=1$, where the nonequilibrium average values are found respectively, [14]

$$
\left\langle\hat{P}_{n}(x)\right\rangle_{\alpha}^{t}=\hat{I}^{\alpha}(1, \ldots, N) \hat{T}(1, \ldots, N) \hat{P}_{n} \rho\left(x^{N} ; t\right) .
$$

$\hat{I}^{\alpha}(1, \ldots, N)$ has the following form for a system of $N$ particles

$$
\hat{I}^{\alpha}(1, \ldots, N)=\hat{I}^{\alpha}(1), \ldots, \hat{I}^{\alpha}(N), \quad \hat{I}^{\alpha}(j)=\hat{I}^{\alpha}\left(\boldsymbol{r}_{j}\right) \hat{I}^{\alpha}\left(\boldsymbol{p}_{j}\right)
$$

and defines operation of integration

$$
\hat{I}^{\alpha}(x) f(x)=\int_{-\infty}^{\infty} f(x) d \mu_{\alpha}(x), \quad d \mu_{\alpha}(x)=\frac{|x|^{\alpha}}{\Gamma(\alpha)} d x .
$$

The operator $\hat{T}(1, \ldots, N)=\hat{T}(1), \ldots, \hat{T}(N)$ defines the operation

$$
\hat{T}\left(x_{j}\right) f\left(x_{j}\right)=\frac{f\left(\ldots, x_{j}^{\prime}-x_{j}, \ldots\right)+f\left(\ldots, x_{j}^{\prime}+x_{j}, \ldots\right)}{2} .
$$

Accordingly, the average value, which is calculated with the relevant distribution function, is defined as

$$
\langle(\ldots)\rangle_{\alpha, r e l}^{t}=\hat{I}^{\alpha}(1, \ldots, N) \hat{T}(1, \ldots, N)(\ldots) \rho_{r e l}\left(x^{N} ; t\right) .
$$

According to Ref. [13], from the extremum of the Renyi entropy functional

$$
\begin{aligned}
L_{R}\left(\rho^{\prime}\right)= & \frac{1}{1-q} \ln \hat{I}^{\alpha}(1, \ldots, N) \hat{T}(1, \ldots, N)\left(\rho^{\prime}(t)\right)^{q} \\
& -\gamma \hat{I}^{\alpha}(1, \ldots, N) \hat{T}(1, \ldots, N) \rho^{\prime}(t) \\
& -\sum_{n} \int d \mu_{\alpha}(x) F_{n}(x ; t) \hat{I}^{\alpha}(1, \ldots, N) \hat{T}(1, \ldots, N) \hat{P}_{n}(x) \rho^{\prime}(t)
\end{aligned}
$$

at fixed values of observed values $\left\langle\hat{P}_{n}(x)\right\rangle_{\alpha}^{t}$ and the condition of normalization

$$
\hat{I}^{\alpha}(1, \ldots, N) \hat{T}(1, \ldots, N) \rho^{\prime}(t)=1,
$$

the relevant distribution function takes the form

$$
\rho_{\text {rel }}(t)=\frac{1}{Z_{R}(t)}\left[1-\frac{q-1}{q} \beta\left(H-\sum_{n} \int d \mu_{\alpha}(x) F_{n}(x ; t) \delta \hat{P}_{n}(x ; t)\right)\right]^{\frac{1}{q-1}},
$$

where $Z_{R}(t)$ is the partition function of the Renyi distribution, which is determined from the normalization condition and has the form

$$
\begin{aligned}
Z_{R}(t)= & \hat{I}^{\alpha}(1, \ldots, N) \hat{T}(1, \ldots, N) \\
& \times\left[1-\frac{q-1}{q} \beta\left(H-\sum_{n} \int d \mu_{\alpha}(x) F_{n}(x ; t) \delta \hat{P}_{n}(x ; t)\right)\right]^{\frac{1}{q-1}} .
\end{aligned}
$$

The Lagrangian multiplier $\gamma$ is determined by the normalization condition

$$
\hat{I}^{\alpha}(1, \ldots, N) \hat{T}(1, \ldots, N) \rho^{\prime}(t)=1 .
$$


The parameters $F_{n}(x ; t)$ are determined from the self-consistency conditions

$$
\left\langle\hat{P}_{n}(x)\right\rangle_{\alpha}^{t}=\left\langle\hat{P}_{n}(x)\right\rangle_{\alpha, r e l}^{t} .
$$

It is important to note that the relevant distribution function corresponded to the Gibbs entropy follows from (8) at $q=1$ [1].

In the general case of the parameters $\left\langle\hat{P}_{n}(x)\right\rangle_{\alpha}^{t}$ of the reduced description of nonequilibrium processes according to (5) and (8), we get the nonequilibrium statistical operator in the form

$$
\rho(t)=\rho_{r e l}(t)+\sum_{n} \int d \mu_{\alpha}(x) \int_{-\infty}^{t} e^{\varepsilon\left(t^{\prime}-t\right)} T\left(t, t^{\prime}\right) I_{n}\left(x ; t^{\prime}\right) \rho_{\text {rel }}\left(t^{\prime}\right) \beta F_{n}^{*}\left(x ; t^{\prime}\right) d t^{\prime},
$$

where

$$
\begin{gathered}
F_{n}^{*}\left(x ; t^{\prime}\right)=\frac{F_{n}\left(x ; t^{\prime}\right)}{1+\frac{q-1}{q} \sum_{n} \int d \mu_{\alpha}(x) F_{n}\left(x ; t^{\prime}\right)\left\langle P_{n}(x)\right\rangle_{\alpha}^{t}} \\
I_{n}\left(x ; t^{\prime}\right)=(1-P(t)) \frac{1}{q} \psi^{-1}(t) i L_{\alpha} \hat{P}_{n}(x)
\end{gathered}
$$

are the generalized flows, $P(t)$ is the Mori projection operator [1], and the function $\psi(t)$ has the following structure

$$
\psi(t)=1-\frac{q-1}{q} \sum_{n} \int d \mu_{\alpha}(x) F_{n}(x ; \dot{t}) P_{n}(x) .
$$

By using the nonequilibrium statistical operator (11), we get the generalized transport equation for the parameters $\left\langle\hat{P}_{n}(x)\right\rangle_{\alpha}^{t}$ of the reduced description,

$$
\begin{aligned}
\frac{\partial}{\partial t}\left\langle\hat{P}_{n}(x)\right\rangle_{\alpha}^{t}= & \left\langle i L_{\alpha} \hat{P}_{n}(x)\right\rangle_{\alpha, r e l}^{t} \\
& +\sum_{n^{\prime}} \int d \mu_{\alpha}\left(x^{\prime}\right) \int_{-\infty}^{t} e^{\varepsilon\left(t^{\prime}-t\right)} \varphi_{P_{n} P_{n^{\prime}}}\left(x, x^{\prime} ; t, t^{\prime}\right) \beta F_{n^{\prime}}^{*}\left(x^{\prime} ; t^{\prime}\right) d t^{\prime},
\end{aligned}
$$

where

$$
\varphi_{P_{n} P_{n^{\prime}}}\left(x, x^{\prime} ; t, t^{\prime}\right)=\hat{I}^{\alpha}(1, \ldots, N) \hat{T}(1, \ldots, N)\left(i L_{\alpha} \hat{P}_{n}(x) T\left(t, t^{\prime}\right) I_{n^{\prime}}\left(x^{\prime} ; t^{\prime}\right) \rho_{r e l}\left(x^{N} ; t^{\prime}\right)\right)
$$

are the generalized transport kernels (the memory functions), which describe dissipative processes in the system. To demonstrate the structure of the transport equations (13) and the transport kernels (14), we will consider, for example, electrodiffusion processes. In the next section, we obtain generalized kinetic equations with fractional derivatives.

\section{Generalized kinetic equation for a nonequilibrium one-particle distribution function with fractional derivatives}

To describe the kinetic processes for the systems of classical particles (gases, liquids) in porous media, one of the main parameters of the reduced description is a nonequilibrium one-particle distribution function $f_{1}(x ; t)=\langle\hat{n}(x)\rangle_{\alpha}^{t}$, where $\hat{n}(x)=\sum_{j=1}^{N} \delta\left(\boldsymbol{r}-\boldsymbol{r}_{j}\right) \delta\left(\boldsymbol{p}-\boldsymbol{p}_{j}\right)=\sum_{j=1}^{N} \delta\left(x-x_{j}\right)$ is the microscopic phase density for number of particles in the system. With such a set of the reduced description 
parameters, the relevant distribution function is as follows:

$$
\rho_{r e l}(t)=\frac{1}{Z_{R}(t)}\left(1-\frac{q-1}{q} \beta\left(H-\int d \mu_{\alpha}(x) a(x ; t) \delta \hat{n}(x ; t)\right)\right)^{\frac{1}{q-1}}
$$

where

$$
Z_{R}(t)=\hat{I}^{\alpha}(1, \ldots, N) \hat{T}(1, \ldots, N)\left(1-\frac{q-1}{q} \beta\left(H-\int d \mu_{\alpha}(x) a(x ; t) \delta \hat{n}(x ; t)\right)\right)^{\frac{1}{q-1}}
$$

is the statistical sum of the relevant distribution function, $\delta \hat{n}(x ; t)=\hat{n}(x)-\langle\hat{n}(x)\rangle_{\alpha}^{t}$ are the density fluctuations and parameter $a(x ; t)$ is determined by the condition of self-agreement:

$$
\langle\hat{n}(x)\rangle_{\alpha}^{t}=\langle\hat{n}(x)\rangle_{\alpha, r e l}^{t} .
$$

It is important to note that when $q=1$ the relevant distribution function (15) in the Renyi statistics transforms into the Gibbs statistics distribution. The distribution (15) can be represented as:

$$
\rho_{\text {rel }}(t)=\frac{1}{Z_{R}(t)}\left(1-\frac{q-1}{q} \beta\left(H-\int d \mu_{\alpha}(x) a^{*}(x ; t) \hat{n}(x)\right)\right)^{\frac{1}{q-1}},
$$

where

$$
\begin{gathered}
Z_{R}(t)=\hat{I}^{\alpha}(1, \ldots, N) \hat{T}(1, \ldots, N)\left(1-\frac{q-1}{q} \beta\left(H-\int d \mu_{\alpha}(x) a^{*}(x ; t) \hat{n}(x)\right)\right)^{\frac{1}{q-1}}, \\
a^{*}(x ; t)=\frac{a(x ; t)}{1+\frac{q-1}{q} \int d \mu_{\alpha}(x) a(x ; t)\langle\hat{n}(x)\rangle_{\alpha}^{t}} .
\end{gathered}
$$

Substituting (18) into (11) we get for the nonequilibrium statistical operator

$$
\rho(t)=\rho_{r e l}(t)+\int_{-\infty}^{t} e^{\varepsilon\left(t^{\prime}-t\right)} T\left(t, t^{\prime}\right) \int d \mu_{\alpha}\left(x^{\prime}\right) I_{n}\left(x^{\prime}, t^{\prime}\right) \rho_{r e l}\left(t^{\prime}\right) \beta a^{*}\left(x^{\prime} ; t^{\prime}\right) d t^{\prime},
$$

where

$$
I_{n}(x ; t)=(1-P(t)) \frac{1}{q} \psi^{-1}(t) i L_{\alpha} \hat{n}(x)
$$

is the generalized flow in which function $\psi(t)$ is equal to

$$
\psi(t)=1-\frac{q-1}{q} \beta\left(H-\int d \mu_{\alpha}(x) a^{*}(x ; t) \hat{n}(x)\right),
$$

$P(t)$ is the projection operator with the following structure:

$$
P(t) \ldots=\int d \mu_{\alpha}(x) \int d \mu_{\alpha}\left(x^{\prime}\right)\langle\ldots \hat{n}(x)\rangle_{\alpha, r e l}^{t}\left[\left\langle\hat{n}(x) \delta\left\{[q \psi(t)]^{-1} \hat{n}\left(x^{\prime}\right)\right\}\right\rangle_{\alpha, r e l}^{t}\right]^{-1} \delta\left\{[q \psi(t)]^{-1} \hat{n}\left(x^{\prime}\right)\right\},
$$

where $\delta\{A\}=A-\langle A\rangle_{\alpha, r e l}^{t}$.

By using the nonequilibrium statistical operator (20) one can obtain for the parameter of reduced description a generalized kinetic equation for the nonequilibrium one-particle distribution function:

$$
\frac{\partial}{\partial t}\langle\hat{n}(x)\rangle_{\alpha}^{t}=\left\langle i L_{\alpha} \hat{n}(x)\right\rangle_{\alpha, r e l}^{t}+\int d \mu_{\alpha}\left(x^{\prime}\right) \int_{-\infty}^{t} e^{\varepsilon\left(t^{\prime}-t\right)} \phi_{n n}\left(x, x^{\prime} ; t, t^{\prime}\right) \beta a^{*}\left(x^{\prime} ; t^{\prime}\right) d t^{\prime},
$$


where

$$
\phi_{n n}\left(x, x^{\prime} ; t, t^{\prime}\right)=\hat{I}^{\alpha}(1, \ldots, N) \hat{T}(1, \ldots, N) i L_{\alpha} \hat{n}(x) T\left(t, t^{\prime}\right) I_{n}\left(x^{\prime} ; t^{\prime}\right) \rho_{r e l}\left(x^{N} ; t^{\prime}\right)
$$

is the generalized transport kernel describing the kinetic processes in which averaging is performed according to power-distribution (18). Exposing the action of the Liouville operator $i L_{\alpha}$ on $\hat{n}(x)$

$$
i L_{\alpha} \hat{n}(x)=-D_{\boldsymbol{r}}^{\alpha} \cdot \boldsymbol{p}(x)-D_{\boldsymbol{p}}^{\alpha} \cdot \boldsymbol{F}(x),
$$

where

$$
\boldsymbol{p}(x)=\sum_{j=1}^{N} \boldsymbol{p}_{j} \delta\left(\boldsymbol{r}-\boldsymbol{r}_{j}\right) \delta\left(\boldsymbol{p}-\boldsymbol{p}_{j}\right), \quad \boldsymbol{F}(x)=\sum_{j=1}^{N} \boldsymbol{F}_{j} \delta\left(\boldsymbol{r}-\boldsymbol{r}_{j}\right) \delta\left(\boldsymbol{p}-\boldsymbol{p}_{j}\right)
$$

is the microscopic density of momentum and force in the phase space of coordinates and momentums of all particles, we get:

$$
\begin{aligned}
\phi_{n n}\left(x, x^{\prime} ; t, t^{\prime}\right)=D_{\boldsymbol{r}}^{\alpha} \cdot D_{p p}\left(x, x^{\prime} ; t, t^{\prime}\right) & \cdot D_{\boldsymbol{r}^{\prime}}^{\alpha}+D_{\boldsymbol{r}}^{\alpha} \cdot D_{p F}\left(x, x^{\prime} ; t, t^{\prime}\right) \cdot D_{\boldsymbol{p}^{\prime}}^{\alpha} \\
& +D_{\boldsymbol{p}}^{\alpha} \cdot D_{F p}\left(x, x^{\prime} ; t, t^{\prime}\right) \cdot D_{\boldsymbol{r}^{\prime}}^{\alpha}+D_{\boldsymbol{p}}^{\alpha} \cdot D_{F F}\left(x, x^{\prime} ; t, t^{\prime}\right) \cdot D_{\boldsymbol{p}^{\prime}}^{\alpha}
\end{aligned}
$$

where $D_{p p}\left(x, x^{\prime} ; t, t^{\prime}\right)$ is the generalized diffusion coefficient and $D_{F F}\left(x, x^{\prime} ; t, t^{\prime}\right)$ is the generalized coefficient of friction in the space of coordinates and momentums, $D_{p F}\left(x, x^{\prime} ; t, t^{\prime}\right)$ describes the spatiotemporal correlations between $\boldsymbol{p}(x)$ and $\boldsymbol{F}(x)$. Substituting (24) and (26) into (22) we get a generalized kinetic equation for a nonequilibrium one-particle distribution function with fractional derivatives

$$
\begin{aligned}
\frac{\partial}{\partial t}\langle\hat{n}(x)\rangle_{\alpha}^{t}= & D_{\boldsymbol{r}}^{\alpha}\langle\boldsymbol{p}(x)\rangle_{\alpha, r e l}^{t}+D_{\boldsymbol{p}}^{\alpha}\langle\boldsymbol{F}(x)\rangle_{\alpha, r e l}^{t} \\
& +\int d \mu_{\alpha}\left(x^{\prime}\right) \int_{-\infty}^{t} e^{\varepsilon\left(t^{\prime}-t\right)}\left(D_{\boldsymbol{r}}^{\alpha} \cdot D_{p p}\left(x, x^{\prime} ; t, t^{\prime}\right) \cdot D_{\boldsymbol{r}^{\prime}}^{\alpha}+D_{\boldsymbol{r}}^{\alpha} \cdot D_{p F}\left(x, x^{\prime} ; t, t^{\prime}\right) \cdot D_{\boldsymbol{p}^{\prime}}^{\alpha}\right. \\
& \left.+D_{\boldsymbol{p}}^{\alpha} \cdot D_{F p}\left(x, x^{\prime} ; t, t^{\prime}\right) \cdot D_{\boldsymbol{r}^{\prime}}^{\alpha}+D_{\boldsymbol{p}}^{\alpha} \cdot D_{F F}\left(x, x^{\prime} ; t, t^{\prime}\right) \cdot D_{\boldsymbol{p}^{\prime}}^{\alpha}\right) \beta a^{*}\left(x^{\prime} ; t^{\prime}\right) d t^{\prime},
\end{aligned}
$$

which takes into account memory effects and spatial inhomogeneity.

\section{Conclusions}

On the basis of approach [1,4] a non-Markov kinetic equation with fractional derivatives for a nonequilibrium one-particle distribution function is obtained. It is important to note that given equation contains the generalized diffusion and friction coefficients in the space of coordinates and momentums of particles and is one of the problems for mathematical modeling in specific applications. One of important application for given equation is describing kinetic processes of particle transport (in particular, of ions) in porous media (with fractal structure), when changes in momentum can significantly change the transport mechanisms.

[1] Kostrobij P., Markovych B., Viznovych O., Tokarchuk M. Generalized diffusion equation with fractional derivatives within Renyi statistics. Journal of Mathematical Physics. 57 (9), 093301 (2016).

[2] Kostrobij P., Markovych B., Viznovych O., Tokarchuk M. Generalized electrodiffusion equation with fractality of space-time. Mathematical Modeling and Computing. 3 (2), 163-172 (2016).

[3] Glushak P. A., Markiv B. B., Tokarchuk M. V. Zubarev's Nonequilibrium Statistical Operator Method in the Generalized Statistics of Multiparticle Systems. Theoretical and Mathematical Physics. 194 (1), 57-73 (2018).

[4] Kostrobij P., Markovych B., Viznovych O., Tokarchuk M. Generalized transport equation with nonlocality of space-time. Zubarev's NSO method. Physica A. 514, 63-70 (2019).

Mathematical Modeling and Computing, Vol. 6, No. 2, pp. 289-296 (2019) 
[5] Kostrobij P., Markovych B., Viznovych O., Zelinska I., Tokarchuk M. Generalized Cattaneo-Maxwell diffusion equation with fractional derivatives. Dispersion relations. Mathematical Modeling and Computing. 6 (1), 58-68 (2019).

[6] Grygorchak I. I., Kostrobij P. P., Stasjuk I. V., Tokarchuk M. V., Velychko O. V., Ivaschyshyn F. O., Markovych B. M. Fizichni procesy ta ih mikroskopichni modeli v periodychnyh neorganichno/organichnih klatratah.Lviv, Rastr-7 (2015), (in Ukrainian).

[7] Kostrobij P. P., Grygorchak I. I., Ivaschyshyn F. O., Markovych B. M., Viznovych O. V., Tokarchuk M. V. Mathematical modeling of subdiffusion impedance in multilayer nanostructures. Mathematical Modeling and Computing. 2 (2), 154-159 (2015).

[8] Grygorchak I. I., Ivaschyshyn F. O., Tokarchuk M. V., Pokladok N. T., Viznovych O. V. Modification of properties of GaSe $\left\langle\beta\right.$-cyclodexterin $\left.\left\langle\mathrm{FeSO}_{4}\right\rangle\right\rangle$ Clathrat by synthesis in superposed electric and light-wave fields. J. Appl. Phys. 121, 185501 (2017).

[9] Kostrobij P., Grygorchak I., Ivashchyshyn F., Markovych B., Viznovych O., Tokarchuk M. Generalized Electrodiffusion Equation with Fractality of Space-Time: Experiment and Theory. Journal of Physical Chemistry A. 122 (16), 4099-4110 (2018).

[10] Zubarev D. N. Modern methods of the statistical theory of nonequilibrium processes. Journal of Soviet Mathematics. 16 (6), 1509-1571 (1981).

[11] Zubarev D. N., Morozov V. G., Röpke G. Statistical mechanics of nonequilibrium processes. Vol. 1. Moscow, Fizmatlit (2002).

[12] Zubarev D. N., Morozov V. G., Röpke G. Statistical mechanics of nonequilibrium processes. Vol. 2. Moscow, Fizmatlit (2002).

[13] Markiv B. B., Tokarchuk R. M., Kostrobij P. P., Tokarchuk M. V. Nonequilibrium statistical operator method in Renyi statistics. Physica A. 390 (5), 785-791 (2011).

[14] Tarasov V.E. Fractional Dynamics: Applications of Fractional Calculus to Dynamics of Particles, Fields and Media. Nonlinear Physical Science. Berlin, Heidelberg, Springer (2010).

[15] Tarasov V. E. Fractional generalization of Liouville equations. Chaos. 14 (1), 123-127 (2004).

[16] Tarasov V. E. Fractional Liouville and BBGKI equations. Journal of Physics: Conference Series. 7 (1), 17 (2005).

[17] Tarasov V.E. Fractional systems and fractional Bogoliubov hierarchy equations. Phys. Rev. E. 71, 011102 (2005).

[18] Kobelev Y.L., Kobelev L. Y., RomanovE.P. Kinetic equations for large systems with fractal structures. Doklady Physics. 45 (5), 194-197 (2000).

[19] Kobelev Y. L., Kobelev L. Y., Kobelev V. L., Romanov E. P. Description of diffusion in fractal media on the basis of the Klimontovich kinetic equation in fractal space. Doklady Physics. 47 (8), 580-582 (2002).

[20] Tarasov V.E. Transport equations from Liouville equations for fractional systems. International Journal of Modern Physics B. 20 (03), 341-353 (2006).

[21] Cottrill-Shepherd K., Naber M. Fractional differential forms. Journal of Mathematical Physics. 42 (5), 2203-2212 (2001).

[22] Mainardi F. Fractional Calculus, pp. 291-348. Vienna, Springer Vienna (1997).

[23] Caputo M., Mainardi F. A new dissipation model based on memory mechanism. Pure and applied geophysics. 91 (1), 134-147 (1971).

[24] Oldham K. B., Spanier J. The Fractional Calculus: Theory and Applications of Differentiation and Integration to Arbitrary Order. Dover Books on Mathematics, Dover Publications (2006).

[25] Samko S. G., Kilbas A. A., Marichev O. I. Fractional Integrals and Derivatives: Theory and Applications. Gordon and Breach Science Publishers (1993). 


\title{
Узагальнене кінетичне рівняння з просторово-часовою нелокальністю
}

\author{
Костробій П. П. ${ }^{1}$, Маркович Б. М. ${ }^{1}$, Рижа I. А. ${ }^{1}$, Токарчук М. В. ${ }^{1,2}$ \\ ${ }^{1}$ Націоналъний університет "Лъвівсъка політехніка", \\ вул. С. Бандери, 12, Лъвів, 79013, Украӥна \\ 2 Інститут фізики конденсованих систем НАН Украӥни, \\ вул. Свенціиъккого, 1, Львів, 79011, Україна
}

\begin{abstract}
Отримано немарковське кінетичне рівняння у дробових похідних для нерівноважної одночастинкової функції розподілу частинок. Отримане рівняння містить узагальнені коефіцієнти дифузії і тертя у просторі координат та імпульсів частинок, це рівняння може бути використане, зокрема, для математичного моделювання кінетичних процесів переносу частинок у пористих середовищах з фрактальною структурою.
\end{abstract}

Ключові слова: кінетичне рівняння, просторово-часова нелокальність, нерівноважна функція розподілу, статистика Рені.

2000 MSC: $82 \mathrm{C} 05,82 \mathrm{C} 70$

удк: 538.93 